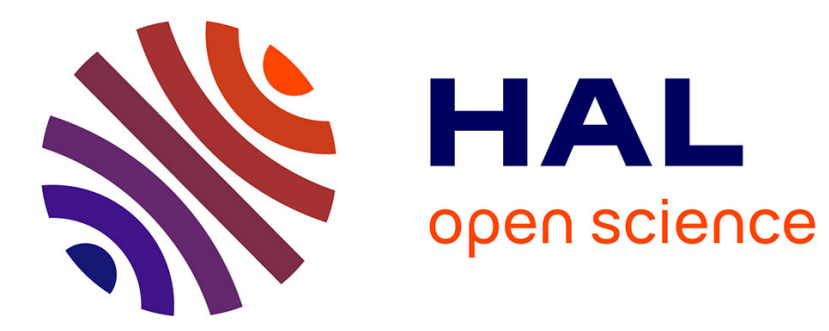

\title{
Modular variable energy post-accelerator linac
}

J. Pottier

\section{To cite this version:}

J. Pottier. Modular variable energy post-accelerator linac. Revue de Physique Appliquée, 1977, 12 (10), pp.1601-1604. 10.1051/rphysap:0197700120100160100 . jpa-00244378

\section{HAL Id: jpa-00244378 https://hal.science/jpa-00244378}

Submitted on 1 Jan 1977

HAL is a multi-disciplinary open access archive for the deposit and dissemination of scientific research documents, whether they are published or not. The documents may come from teaching and research institutions in France or abroad, or from public or private research centers.
L'archive ouverte pluridisciplinaire HAL, est destinée au dépôt et à la diffusion de documents scientifiques de niveau recherche, publiés ou non, émanant des établissements d'enseignement et de recherche français ou étrangers, des laboratoires publics ou privés. 


\title{
MODULAR VARIABLE ENERGY POST-ACCELERATOR LINAC
}

\author{
J. POTTIER \\ Service d'Électronique de Saclay, Centre d'Études Nucléaires de Saclay, \\ B.P. 2, 91190 Gif sur Yvette, France
}

\begin{abstract}
Résumé. - On donne un aperçu d'un accélérateur linéaire à énergie variable de conception modulaire.

On peut le définir par les caractéristiques suivantes :

1. Sa conception modulaire, qui permet des extensions faciles, avec des amplificateurs H.F. et des dispositifs de réglage de l'amplitude et de la phase identiques.

2. L'usage de cavités longues de quelques mètres, dont la longueur est choisie :

a) assez longue pour utiliser un nombre modéré de sections,

b) assez courte pour être compatible avec :

Une focalisation externe économique, qui permet des tubes de glissement de faible diamètre extérieur, d'où une bonne impédance-shunt.

Une bonne résolution de l'énergie, dont la variation est obtenue très simplement.

Par exemple, 5 telles sections (fréquence : $100 \mathrm{MHz}$, puissance H.F. : $30 \mathrm{~kW}$, longueur : $4 \mathrm{~m}$, diamètre : $80 \mathrm{~cm}$ ) doivent accélérer ${ }^{40} \mathrm{Ca}$ de $1,8 \mathrm{MeV} / A$ à des énergies comprises entre 1,8 et $8 \mathrm{MeV} / A$ avec une résolution d'énergie meilleure que $10^{-3}$.
\end{abstract}

Abstract. - General outlines of a variable energy linac of modular design are given.

It may be characterized by the following topics:

1. The modular conception, which affords the ability for easy extensions, with identical R.F. amplifiers and amplitude and phase control devices.

2. The use of cavities some meters long, the length of which being chosen:

a) long enough to use a moderate number of sections,

b) short enough to be compatible with:

A cheap external focusing, which allows a small outside diameter for the drift tubes and therefore a good shunt-impedance.

A good resolution of the energy, the variation of which being obtained by a very simple mean.

For instance, 5 such sections, (frequency: $100 \mathrm{MHz}$, R.F. power: $30 \mathrm{~kW}$, length: $4 \mathrm{~m}$, diameter: $80 \mathrm{~cm}$ ) are expected to accelerate ${ }^{40} \mathrm{Ca}$ from $1.8 \mathrm{MeV} / A$ to energies comprised between 1.8 and $8 \mathrm{MeV} / A$ with an energy resolution better than $10^{-3}$.

1. Economic considerations. - The price of an accelerating section may be looked as the sum of two terms.

$P=P_{1} \times L+P_{\mathrm{RF}} \times W$

The first one includes parts the price of which is roughly proportional to the length $L$ of the section: Buildings, mechanics, etc.

The second one consists of R.F. equipment and related devices (cooling, etc.), the value of which increases with the R.F. power $W$.

The voltage obtained with such a section is

$$
V=\left(Z_{\text {eff }} W L\right)^{1 / 2}
$$

where $Z_{\text {eff }}$ is the effective shunt impedance. It appears that for a given voltage the product $W L$ must be kept constant.

It results from equation (1), that if the price of the kilowatt of R.F. is invariable the lower price is obtained when $P_{1} \times L=P_{\mathrm{RF}} \times W$, i.e. when both prices are equal, whatever the shunt-impedance may be.
Actually, the price of a R.F. amplifier is roughly proportional to the square root of its power.

It ensues that in this case, the total price of the section is optimized if the price of the R.F. power is twice this of the other parts.

These optima are rather flat: for instance, for the choice of a power twice lesser that the optimum one in the second case, the total price is only $14 \%$ greater than the minimum.

Other considerations that the least investment may lead to other choices: For instance, a length greater than the optimum decreases the waste of energy.

From equation (2), one may see that, for a given price of a unit length of structure, the price of the $\mathrm{MeV}$ is inversely proportional to the shunt-impedance.

It shows the interest of obtaining a good shuntimpedance, if this quality does not increase too much the price of the structure.

2. Type of structure. - For a number of considerations (very high shunt-impedance in the energy-range 


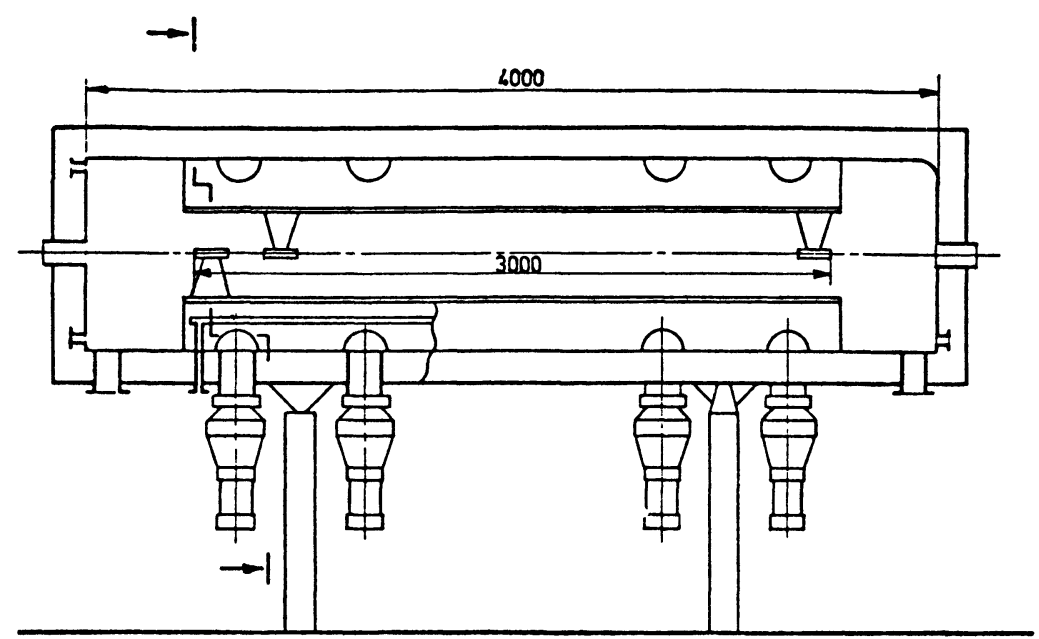

FIG. 1. - View of a cavity.

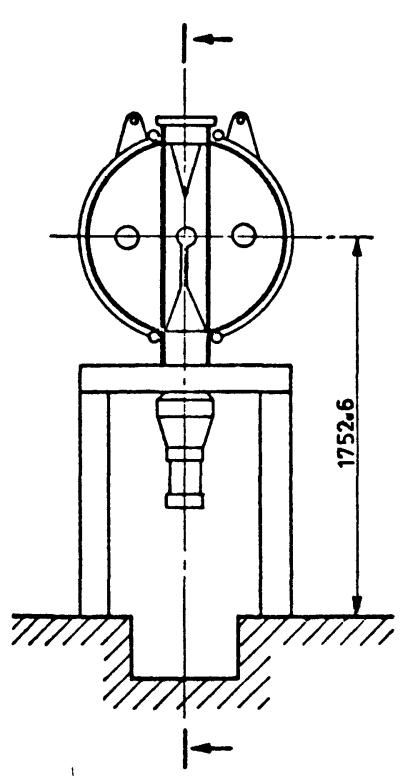

to be obtained, small diameter, easiness of building, good mode-separation, ability to adjust the field distribution, etc.), we choosed a transverse-electric field cavity we proposed and studied long ago, and which has been successfully experimented by Dr. Morinaga and his team. The sketch of such a cavity may be seen in figure 1.

Figure 2 shows the shunt-impedance of three models of such cavities according to the velocities

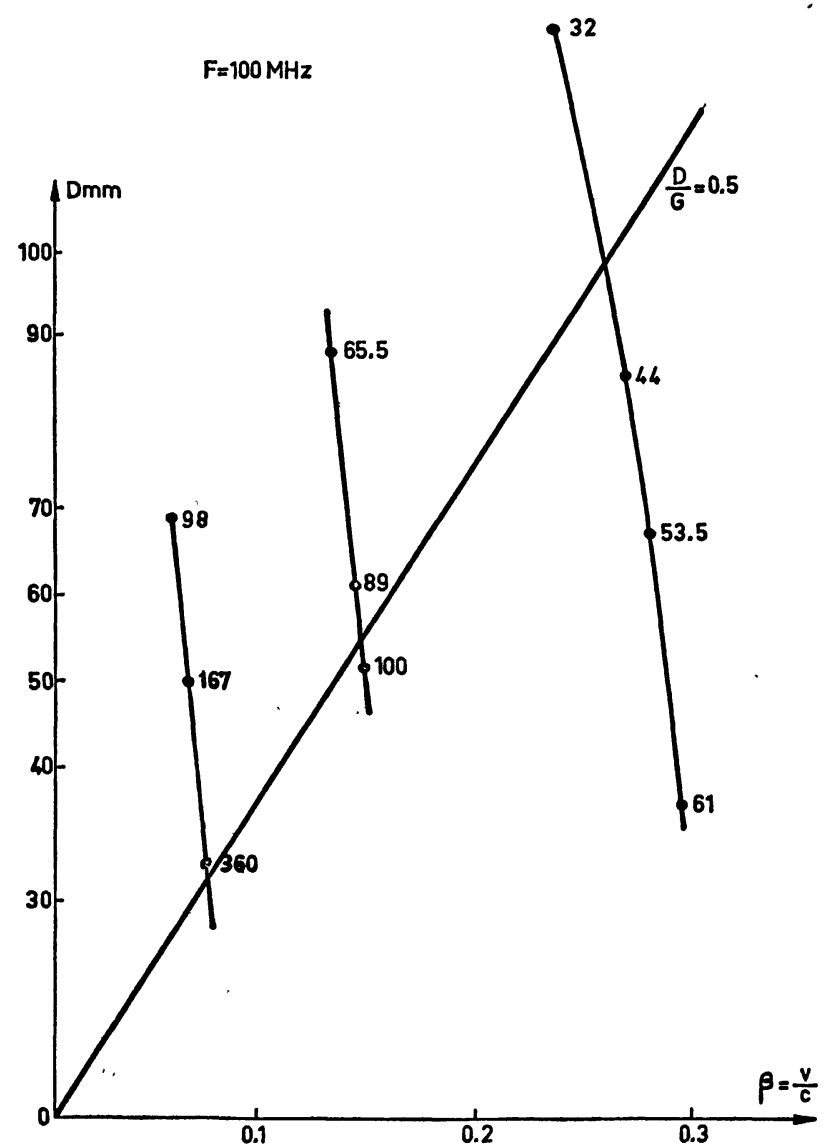

Fig. 2. - Experimental shunt - impedances $(\mathrm{M} \Omega / \mathrm{m})$ for 3 structures. of the ions $\left(\beta=\frac{V}{C}\right)$ and the diameter of the drift tubes, for a frequency of $100 \mathrm{MHz}$ and lengthes of the drift tubes equal to the gap.

One may see the great interest of using drift tubes diameters as small as possible in order to obtain a good shunt-impedance.

A normalized curve of the shunt-impedance versus the ratio $\frac{D}{G}$ of the drift tube diameter to the gap is plotted figure 3 .

Nethertheless, the ratio $\frac{D}{G}$ must not be smaller than about 0.5 . Otherwise, the inhomogeneity of the field in the gap becomes too big : the peak field increases for a given mean field, and the transit time factor is impaired.

3. Focussing. - An outside diameter of drift tubes of a few centimeters $(3.5 \mathrm{~cm}$ e.g.) implies an external focussing.

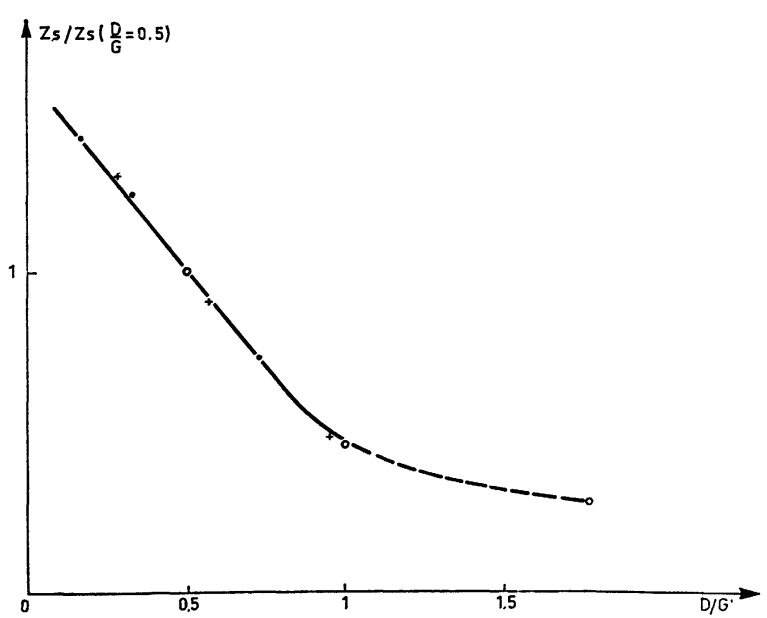

FIG. 3. - Normalized shunt - impedances for 3 structures. 
The defocusing field is proportional to the distance of the particle off the axis. At first approximation (constant field, phase and velocity) the trajectory of a particle is a combination of hyperbolic lines. The smallest perturbation from a straight line is obtained when this trajectory is roughly a hyperbolic sine, crossing the axis at the middle of the cavity, i.e. if the beam is focused on the axis in the middle part of the cavity. At a great distance from this point, the radius grows practically in an exponential way, but for short enough a cavity the trajectory does not depart too much from a straight line. For instance, for a small synchronous phase $\left(-10^{\circ}\right)$, a frequency of $100 \mathrm{MHz}$, a useful length of $3 \mathrm{~m}$ is convenient for particles of $2 \mathrm{MeV} / A$.

Simulation shows that such a focusing, obtained by one triplet between cavities, is not at all critical, and that actually the emittance of the beam is greatly improved from the input to the output of an accelerator made of several cavities, which was not obvious in this case because the process is not adiabatic and Liouville's theorem does not apply.

An additional benefit of such an arrangement is a simpler building of the cavities.

4. Energy variation. - If the field in a cavity is lesser than necessary to obtain a stable acceleration of the particles, it appears that the energy of a particle at the output is a function of the relative phase of the field and the particle at the input. This function presents a maximum for some value of this phase, for which it is stationary.

For a short enough cavity, this stationarity covers sufficient field to insure a good energy resolution for a short bunch (e.g. $<20^{\circ}$ ).

Computation performed on simulated models confirmed that energy must be adjusted in a very simple way by controlling the amplitude and the phase of the R.F. fed to the last cavity in use, and that by using a debuncher a good energy resolution $\left(<10^{-3}\right)$ may be obtained, this resolution depending mainly upon the quality of bunching.

5. Frequency and length of the structure. - Emittance characteristics of the beam show that a beam diameter smaller than $2 \mathrm{~cm}$ may be obtained with a distance of $5 \mathrm{~m}$ between focusing lenses, which affords the possibility of using cavities $4 \mathrm{~m}$ long. For about $2 \mathrm{MeV} / A$, a proper energy resolution may be obtained in this case with a frequency of $100 \mathrm{MHz}$.

It happens that such cavities provide a good balance of price, according to $\S 1$, with the price of commercially available R.F. amplifiers of about $30 \mathrm{~kW}$, which afford the lower cost of the kilowatt.

For higher energies, it would be probably more convenient to use higher frequencies, $200 \mathrm{MHz}$ for instance.

6. Outlines of the post-accelerator. - In order to show the possibilities afforded by such an arrange- ment, we shall consider the case of a post-accelerator basically designed for ${ }^{40} \mathrm{Ca}$ and lighter elements.

We supposed that the ratio of the number of electronic charges to the number of mass $A$ after stripping is $\frac{q}{A} \geqslant 0.375$ and the energy per nucleon at least $1.8 \mathrm{MeV} / A$ at the input.

Five cavities (outer length $4 \mathrm{~m}$, usefull length $\simeq$ $3 \mathrm{~m}$, diameter $\simeq 0.75 \mathrm{~m}$ ) fed by $30 \mathrm{~kW}$ R.F. each are needed to bring the energy to little more than $8 \mathrm{MeV} / A$ (Fig. 4).

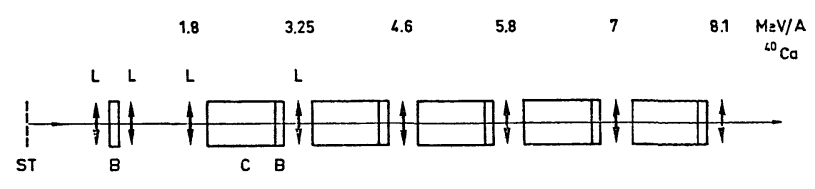

FIG. 4. - Block diagram of the post - accelerator.

The mean effective accelerating field, $1.28 \mathrm{MV} / \mathrm{m}$ for the first cavity, decreases to $1 \mathrm{MV} / \mathrm{m}$ for the last one because of the decrease of the shunt-impedance with the particle velocity.

The actual mean electric field is about $15 \%$ greatèr, i.e. $\simeq 1.47 \mathrm{MV} / \mathrm{m}$ for the first cavity, because of the $\cos \varphi$ and transit time factors.

Lighter elements may be accelerated to energies a little higher, for instance $15 \%$ for carbon by somewhat outphasing the field.

For heavier elements, ${ }^{56} \mathrm{Fe}$ for instance, it is necessary to add a cavity before the first one, and to increase the field in the cavities, because of the lower $\frac{q}{A}$ ratio.

This may be obtained by using amplifiers in a pulsed mode, or by doubling the R.F. amplifiers, which affords the possibility of multiplying the field by $\sqrt{2}$ (which is still compatible with cold field emission and sparking criteria), and so of using particle having a $\frac{q}{A}$ ratio $\sqrt{2}$ times smaller.

For heaviest elements, heavier than $127 \mathrm{I}$ for instance, it would be necessary to add one more cavity and an other stripper.

An other way for accelerating heavier elements may be using lower frequencies:

This may be obtained by a capacitive loading of the cavity: it has been shown [1] that such a loading may be used to lower the resonance frequency of a cavity by a ratio of $\sqrt{2}$ without a too big impairing of the shunt-impedance.

It ensues that, with the same field, particles having a $\frac{q}{A}$ about twice smaller may be accelerated to energies in the same ratio.

Lowering the frequency of the cavities may be obtained, too, by introducing sleeves between the 
central part of the cavity and the two side shells, without any degradation of the electric quality of the cavity in this case.

A last way for adjusting the ability of the cavities to accelerate properly particles of very different $\frac{q}{A}$ consists of using a versatile arrangement of drift tubes as made by Dr. Morinaga and his team.

7. Conclusion. - The proposed arrangement affords a very simple and economical mean of building a post-accelerator.

The R.F. power needed $(150 \mathrm{~kW}$ for the cited configuration) is low, compared with other conventional solutions, and may be supplied by a small number of identic commercially available amplifiers, cheap and reliable.
For a given particle, phase and R.F. level have to be adjusted only in the last cavity in use.

An array of a number of independant cavities looks to offer a more flexible use according to the $\frac{q}{A}$ ratio, mainly for lighter particles.

For instance, if designed for accelerating ${ }^{40} \mathrm{Ca}$, $\frac{q}{A}=0.375$, to $8.1 \mathrm{MeV} / A$, it would be able of accelerating ${ }^{12} \mathrm{C}$ to $10.8 \mathrm{MeV} / A$ instead of $9.32 \mathrm{MeV} / A$ in our case.

Nethertheless, a machine accelerating ${ }^{12} \mathrm{C}$ to $10.8 \mathrm{MeV} / A$ and consequently ${ }^{40} \mathrm{Ca}$ to $9.4 \mathrm{MeV} / A$ instead of 8.1 , built as proposed, would be, to be sure, very less expensive to build and to run (about $150 \mathrm{~kW}$ R.F. instead of some hundreds $\mathrm{kW}$ ) and, I think, more reliable.

\section{References}

[1] Chabert A., Voisin G. and Pottier J., NIM - NUIMA 115 (2) (1974), 471. 